\title{
The Development of Writing Skills in Individuals with Learning Difficulties: An Introduction
}

\author{
Peggy McCardle, Vincent Connelly and Brett Miller*
}

This volume highlights writing development and its relation to other cognitive domains, such as language and reading, for individuals who struggle to acquire writing proficiency, including those with specific learning disorders (SLD; e.g., dyslexia, dysgraphia, and specific language impairment) which affect writing skills (e.g., handwriting, composition). Writing and writing development are presented from a trans-national perspective with an integrated focus on conceptualizing writing as a developmental process. This trans-national perspective from across six European nations, Australia and the United States seeks to capture those essentials of instruction and intervention in writing that seem to be cross-cutting rather than language or culture specific, in order to facilitate a cohesive and integrative discussion of issues relevant to the acquisition of writing skills.

Focused primarily on struggling writers or individuals with SLD, this volume seeks to complement existing resources, such as the Handbook of Writing Research 2nd edition (MacArthur, Graham, \& Fitzgerald, 2016) or those focused on improving writing in typically developing students (e.g., Graham \& Harris, 2005; Miller, McCardle, \& Long, 2014), The authors in this volume primarily target professionals working with developing writers (e.g., educators, speechlanguage pathologists, occupational therapists) and writing researchers, with many of the contributing authors highlighting implementations of specific intervention programs. This volume systematically highlights and links to major writing research domains, with a thematic focus on the development of writing skills in individuals who struggle, complementing the foci of the other recent volumes of the "Studies in Writing" series. As part of the "Studies in Writing" series, this volume extends the focus to be encompassing of struggling writers, who are often overlooked in writing education and research.

* The opinions and assertions presented in this article are those of the authors and do not purport to represent those of the Eunice Kennedy Shriver National Institute of Child Health and Human Development, the U.s. National Institutes of Health, or the U.s. Department of Health and Human Services.

(C) KONINKLIJKE BRILL NV, LEIDEN, 2018 | DOI: 10.1163/9789004346369_002

This is an open access chapter distributed under the terms of the prevailing CC-BY-NC License at the time of publication. 
To address writing development, both for typically developing learners and those who struggle, it is important to have a clear conceptualization of writing itself. In part 2, two sets of authors address models of writing. O'Rourke, Connelly, and Barnett (Chapter 2) outline the recent cognitive model of writing development put forward by Hayes and Berninger (2014), and discuss its relevance and application to those with SLD and the ambiguities and information gaps in this and other cognitive models as they apply to struggling writers. The authors conclude that simply relying on the diagnostic labels of children who struggle to write (e.g., dyslexia, language learning disorder) to determine writing interventions will only take us so far. To go further requires not only knowledge of the child's needs but also an understanding of writing gained through current and continued enhancements of models of writing. Complementing this chapter, Wengelin and Arfé (Chapter 3) address the relation of reading to writing and highlight links between difficulties in each of those abilities. Taking a developmental approach, these authors discuss models that explain reading and writing difficulties at the word and text level, and how we might best understand the relations between reading and writing processes within these models, as well as implications for assessment. The importance of achieving a balance between instruction in oral language, reading and writing skills throughout development is emphasised, as well as the interactive nature of the development of spoken and written language systems.

It is a natural progression from models of writing to part 3's discussion of writing development itself. Tolchinsky and Jisa (Chapter 4) provide an overview of the development of writing systems as a mode of communication, before transitioning to a developmental perspective of how individuals learn to write. The authors describe the move from early pre-writing through emergent writing and invented spelling, tracing the parallel between the development of graphic signs and the representational function of writing. Further to this, these authors explore the linking of early writing to language, and how linguistic and cognitive abilities influence writing - how children learn to use writing as a productive means of communication and how they acquire meta-knowledge about writing. Making the point that strategic learning relies on writers' $\operatorname{cog}$ nitive abilities and their experiences, self-efficacy, and motivation, Gregg and Nelson (Chapter 5 ) review empirical work in each of these areas as they relate to writing in adolescents and adults. After defining written expression, they discuss persistence, self-regulation, and self-efficacy, linking these to a writer's sense of audience, text structure, and even how today's student writers must learn to handle multimodal information in our technological age. Then as promised, they review empirical studies on writing in individuals with learning disorders; they include in this review studies of handwriting, spelling, punctu- 
ation and grammar, discourse, cohesion, and writing fluency. Lamenting the dearth of research addressing what they see as key areas that contribute to writing, they call specifically for more research addressing the difficulties that students with SLD face when learning to write. Gregg and Nelson conclude by making the important point that it is assumed that most writing interventions will have an impact on the executive processing skills of struggling writers, but that there is, in fact, a dearth of solid evidence to support this assumption.

In part 4, Instruction and Intervention Approaches, are three chapters addressing a range of approaches to assisting struggling writers. In Chapter 6, Silliman and colleagues argue that writing should be conceptualized as a multidimensional communication process expressed through spelling, and discuss the importance of spelling to writing, where spelling includes significant work on morphology and word derivations. The triple word form theory (Bahr, Silliman, \& Berninger, 2009; Bahr, Silliman, Berninger, \& Dow, 2012; Garcia, Abbott, \& Berninger, 2010) then forms the basis of writing instruction for those with spelling and language learning difficulties. They conclude that a basic knowledge of spelling patterns helps both typical and struggling writers to successfully develop the key translation skills that they will require for the more complex aspects of producing meaning in writing - even today with the many technological tools available to writers to support their spelling.

Technological tools are the focus of the work presented by Rønneberg and colleagues (Chapter 7 ) who argue that too many young writers, especially those with SLDS, receive more negative than positive feedback on their writing, and that their potential as writers is not well-supported by current technologies. These authors outline solutions based on evidence from studies of writers, in which struggling writers can be moved forward by accepting "good enough" products and providing reinforcement for what is accomplished, separating writing from editing, and setting successive goals-thus truly implementing a developmental approach to instruction. The emphasis here is on the writers getting what is needed from supportive technology so that they are motivated and empowered to continue writing. For this to happen, the authors argue that current tools need to focus not just on readers but also on the needs of struggling writers.

Unfortunately, struggling writers are precisely the group that is most often overlooked in the classroom. During a typical day in secondary education, these students move from one subject-specific class to another where teaching staff often miss these students' writing difficulties. This lack of attention to the needs of adolescent writers is reflected in a recent $\mathrm{UK}$ study demonstrating that children with SLD made no progress in writing during their period of secondary 
education from age 11 to 16 (Dockrell, Lindsay \& Connelly, 2009). Myhill and Jones (Chapter 8) convincingly lay out the complexity of writing, describe the characteristics of struggling adolescent writers, and offer approaches to supporting these adolescents as they work to develop their writing abilities. The authors discuss at length the importance of developing and supporting metalinguistic skills in these adolescents and provide their own data on the effectiveness of putting support into action in this area.

In the current anti-testing climate, assessment is not always a popular topic, yet it remains an essential one. Assessment provides our primary tool to gauge progress and evaluate the success of a student, a process, or a program. Assessment results can provide key formative and summative information to help determine a learner's needs and potentially to provide insight on how to address them. Part 5 aims to highlight the role of assessment of writing from multiple viewpoints. In Chapter 9, Rose provides an example of the role of assessment in an integrative program on writing. The heart of the author's discussion is not about assessing the student or the program but the actual task of learning. He illustrates this via a social theory of learning and a functional theory of language, and describes a program of reading and literacy development for indigenous students who were lagging behind their non-indigenous peers. Rose leads us through the steps in a writing program for these students, and based on the success of both the reading and writing components of this program, argues that many indigenous students who have been diagnosed as SLD are more likely suffering from ineffective instruction. His assessment of tasks has led to a functional program that, using assessments developed to measure student progress in reading and writing, demonstrates student success.

Chapter 10, the second chapter in the Assessment part, discusses the role of curriculum-based measures in assessing writing. Dockrell, Connelly, Walter, and Critten highlight the importance of valid and reliable assessments of the products of students' writing efforts, and the key value of providing instruction and intervention targets. After a discussion of various approaches to assessment, and the value of formative assessment, these authors present their own work to examine the potential of a writing curriculum-based assessment (свм$\mathrm{w}$ ), which they found to be useful in differentiating those with SLD; they are continuing to refine and study this measure. Curriculum based assessment is not without disadvantages or critics, but it does focus on measuring change in writing and can provide a limited basis for comparisons across teaching systems and languages.

The chapters contributing to this volume address many important areas, but it is clear that the study of writing difficulties is clearly in need of more unified 
and systematic research. The final chapter provides an agenda for promoting transdisciplinary and trans-national research and practice collaborations, with the hope that such work can help to unify the field's view of writing development for SLD learners. We review critical unresolved challenges as well as new challenges that can be expected, and offer a model for moving forward.

\section{References}

Bahr, R.H., Silliman, E.R., \& Berninger, V.W. (2009). What spelling errors have to tell about vocabulary learning. In C. Wood, \& V. Connelly (Eds.), Reading and spelling: Contemporary perspectives (pp. 109-129). New York, NY: Routledge.

Bahr, R.H., Silliman, E.R., Berninger, V.W., \& Dow, M. (2012). Linguistic pattern analysis of misspellings of typically developing writers in grades 1-9. Journal of Speech, Language, and Hearing Research, 55, 1587-1599. doi:10.1044/1092-4388(2012/10-0335)

Dockrell, J.E., Lindsay, G. \& Connelly, V. (2009). The impact of specific language impairment on adolescents written text. Exceptional Children, 75, 427-426.

Garcia, N., Abbott, R.D., \& Berninger, V.W. (2010). Predicting poor, average, and superior spellers in grades 1-6 from phonological, orthographic, and morphological, spelling, or reading composites. Written Language \& Literacy, 13, 61-98.

Graham, S., \& Harris, K.R. (2005). Writing better: Teaching writing processes and selfregulation to students with learning problems. Baltimore: Paul H. Brookes Publishing.

Hayes, J.R. \& Berninger, V. (2014). Cognitive process in writing: A framework. In B. Arfé, J.E. Dockrell \& V.W. Berninger (Eds.), Writing development in children with hearing loss, dyslexia or oral language problems: Implications for assessment and instruction (pp. 3-15). New York: Oxford University Press.

MacArthur, C., Graham, S., \& Fitzgerald J. (2016). Handbook of writing research, 2nd Edition. New York: Guilford Publications.

Miller, B., McCardle, P., \& Long, R. (Eds.) (2014). Teaching reading and writing:Improving instruction and student achievement. Baltimore, MD: Paul H. Brookes Publishing.

Nagy, W., Berninger, V.W., \& Abbott, R.D. (2006). Contributions of morphology beyond phonology to literacy outcomes of upper elementary and middle-school students. Journal of Educational Psychology, 98, 134-147. 